\title{
Территориальность интеллектуальной собственности на современном этапе
}

Леанович Е.Б. ${ }^{*}$

Статья посвящена анализу территориальности интеллектуальной собственности в условиях глобализации. Автор выявляет основания для применения коллизионных норм к интеллектуальной собственности. Осуществляется сравнительный анализ положений российского права (третьей и четвертой частей Гражданского кодекса Российской Федерации) и права других государств (Республики Беларусь и Украины). Доказывается возможность и целесообразность применения иностранного права по некоторым вопросам интеллектуальной собственности.

Автор показывает закономерность постепенного ограничения территориальности интеллектуальной собственности с помощью методов международно-правового регулирования на примере наиболее авторитетных международных соглашений по вопросам интеллектуальной собственности. Отмечается, что в настоящий момент заключение новых международных соглашений, ограничивающих территориальность интеллектуальной собственности, маловероятно. Делается вывод, что отказ от территориальности интеллектуальной собственности будет развиваться в национальном праве и судебной практике.

Ключевые слова: интеллектуальная собственность; коллизионные вопросы интеллектуальной собственности; международная охрана интеллектуальной собственности; территориальный характер интеллектуальной собственности; глобализация.

Национальные законы об интеллектуальной собственности не действуют экстерриториально - они не применяются на иностранной территории. Лицо, чьи права на объект интеллектуальной собственности охраняются в одном государстве, не может рассчитывать на то, что охрана этого объекта на тех же условиях и в том же объеме обязательно действует в других государствах. В литературе принцип территориальности традиционно иллюстрируется на примере промышленной собственности ${ }^{1}$. Регистрация и выполнение других формальностей в одном

\footnotetext{
* Леанович Елена Борисовна - к.ю.н., доцент кафедры международного частного и европейского права факультета международных отношений Белорусского государственного университета. leanovich@rambler.ru.
} 
государстве не являются основанием для автоматического предоставления охраны в другом государстве. Но и в авторском праве территориальные ограничения осложняют испрашивание охраны в нескольких государствах. Даже если какие-то факты, имевшие место в рамках иностранной юрисдикции, принимаются во внимание, правила, условия, порядок охраны прав интеллектуальной собственности не определяются иностранным правом.

Территориальность интеллектуальной собственности значительно отличает ее от собственности материальной. Вещные права в гораздо меньшей степени, чем интеллектуальные права, уязвимы в международном обороте. Перемещение через национальные границы материальных объектов (машин, оборудования, картин, книг и т.д.) не влечет прекращения вещных прав, возникших по законам иностранного государства. Наличие же интеллектуальных прав на нематериальные объекты, воплощенные в этих вещах, ставится под сомнение и оценивается через призму правовой системы государства по месту испрашивания охраны.

Основной причиной территориальности интеллектуальной собственности является задача, которая стоит перед любым государством, обеспечение приоритетов своего экономического развития. Монополия, предоставляемая государством правообладателю, необходима для стимулирования инвестиций в интеллектуальные достижения. Но в этом процессе государство оказывает поддержку в первую очередь своим лицам, поскольку охрана прав интеллектуальной собственности иностранцев предполагает ограничение доступа отечественных лиц к мировым интеллектуальным достижениям.

Анализ развития правового регулирования интеллектуальной собственности в разных странах показывает, что с самого начала направляющей и движущей силой этого процесса стали интересы государственной экономической политики ${ }^{2}$. В настоящий момент обострение конкуренции государств в инновационном развитии и необходимость поддержки национальных правообладателей не способствуют отказу от территориальности в охране прав интеллектуальной собственности. В то же время территориальность интеллектуальной собственности

1 Dinwoodie, Graeme B. Trademarks and territory: detaching trademark law from the nationstate / Graeme B. Dinwoodie // Houston law review. 2004. Vol. 41. № 10-11. P. 887-973.

2 Территориальная природа интеллектуальной собственности / Публикация ВОИС «Интеллектуальная собственность в Интернет: обзор проблем». 2002 г. [Электронный peсурс]. Режим доступа: http://ilex.com.ua/view/intelect-article/browse/1/article/64.html. (дата обращения: 27.07.08). 
не отвечает современным вызовам глобализации. Она противоречит процессам интернационализации культурной, информационной, научно-технической и экономической жизни общества. В научно-правовой литературе все чаще высказывается мнение, что территориальность интеллектуальной собственности в современном обществе является анахронизмом и пережитком прошлого ${ }^{3}$. Безусловно, такой подход является слишком радикальным. Поэтому в современном мире территориальное признание прав интеллектуальной собственности в значительной степени облегчается применением механизмов международного и национального права.

Преодоление территориального характера прав интеллектуальной собственности стало осуществляться с помощью методов международно-правового регулирования с конца XIX в. За более чем вековую историю развития сложилась стройная система международного сотрудничества по вопросам интеллектуальной собственности. Центром данной системы является Всемирная Организация Интеллектуальной Собственности (ВОИС), к ведению которой относится около трех десятков универсальных соглашений по различным вопросам интеллектуальной собственности. Значительным достижением в развитии международного сотрудничества в области интеллектуальной собственности является Соглашение по торговым аспектам прав интеллектуальной собственности (ТРИПС), заключенное в рамках ВТО. Есть также значительное число региональных и двусторонних соглашений, посвященных различным вопросам интеллектуальной собственности.

Международные соглашения минимизируют негативные аспекты территориального характера интеллектуальных прав и позволяют:

- обеспечивать доступ иностранцев к национально-правовым системам охраны (национальный режим, режим наибольшего благоприятствования);

- сокращать материальные и временные издержки в процессе оформления прав в нескольких государствах (право приоритета, международные системы регистрации, патентования и депонирования);

- учитывать некоторые обстоятельства правовой охраны объектов интеллектуальной собственности по иностранному праву.

Значительны успехи международно-правового регулирования в целях преодоления территориального характера прав интеллектуальной

${ }^{3}$ Marshall Leaffer A. The Law World of Internet. Trademark Law // Intellectual Property Law Review. 1998. Vol. 1. № 28. P. 28. 
собственности на региональном уровне. В частности, региональная патентная кооперация, единообразно действующая во всех странах членах ЕС, единая система правовой охраны товарных знаков и промышленных образцов Сообщества в значительной степени позволяют дистанцировать охрану прав интеллектуальной собственности в международном обороте от национально-правовых систем. Универсальные международно-правовые механизмы в основном затрагивают только процесс признания прав интеллектуальной собственности за иностранцами и облегчают его осуществление в нескольких государствах. После этого практически все вопросы: объем правомочий, срок охраны, средства правовой защиты и т.д. - регулируются национальным правом.

Парижская конвенция по охране промышленной собственности 1883 г. и Бернская конвенция об охране литературных и художественных произведений 1886 г. существенно ограничили территориальный принцип охраны исключительных прав. Национальный режим, конвенционное право приоритета и другие правовые механизмы первых базовых международных договоров в области интеллектуальной собственности расширили охрану в иностранных государствах за пределами юрисдикции государства национальности правообладателя или места возникновения охраны. Одно из старейших международных соглашений в области интеллектуальной собственности, Международное соглашение о международной регистрации знаков 1891 г., предоставило возможность получения охраны в нескольких государствах на основе одной процедуры.

В развитии международного права интеллектуальной собственности прослеживается тенденция продолжать последовательное снятие территориальности интеллектуальной собственности. Так, согласно Гаагскому акту о пересмотре Парижской конвенции 1925 г. в нее вошла ст. 6 bis, предусматривающая возможность предоставления охраны знаку без регистрации в результате того, что он приобрел международную известность. В Берлинской редакции Бернской конвенции 1908 г. был осуществлен отказ от принципа предоставления авторскоправовой охраны в зависимости от выполнения формальностей, предусмотренных в стране первой публикации. Постоянно расширяется и совершенствуется система универсальных и региональных соглашений, предусматривающих международные процедуры оформления прав на объекты промышленной собственности. В 1925 г. принято Гаагское соглашение о международном депонировании промышленных 
образцов, в 1970 г. заключен Вашингтонский договор о патентной кооперации, в 1977 г. подписан Будапештский договор о международном признании депонирования микроорганизмов для целей патентной процедуры, в 1994 г. создана Евразийская патентная система и т.д.

Однако, несмотря на большое количество международных договоров, способствующих преодолению территориальности интеллектуальной собственности, основное ее проявление остается. Практически все вопросы предоставления охраны и осуществления защиты прав интеллектуальной собственности решаются национальным правом государства, в рамках юрисдикции которого заявлены соответствующие требования.

Международные соглашения по вопросам интеллектуальной собственности признают территориальное ограничение ее охраны. Наиболее очевидным образом это проявляется применительно к объектам промышленной собственности. В ст. 4-bis Парижской конвенции закреплен принцип независимости патентов: патенты, заявки на которые поданы в разных государствах-участниках, независимы от патентов, полученных на то же изобретение в других странах, как по основаниям недействительности, так и по сроку действия патента. Причем в п. 5 данной статьи специально оговорено, что получение патента с преимуществом, вытекающим из приоритета, не влияет на срок действия патента в разных странах.

Однако и Бернская конвенция, отказавшаяся от формальных требований, в меньшей степени, чем Парижская конвенция, но все же признает территориальность авторского права. Согласно п. 1-3 ст. 5 Бернской конвенции, предоставление авторско-правовой охраны и по принципу гражданства, и по принципу происхождения произведения означает прежде всего применение национального права по месту испрашивания охраны.

Мадридское соглашение содержит некоторые материальные правила, действующие единообразно во всех государствах, где знак получает охрану на основе международной регистрации, - срок действия регистрации и ее продления (ст. 6 и 7). Вместе с тем ст. 4 Мадридского соглашения свидетельствует, что оно исходит из признания территориальности охраны. Согласно этой статье последствием международной регистрации в странах, для которых она осуществлена, является предоставление знаку такой же охраны, как если бы он был заявлен там непосредственно. 
Вашингтонский договор о патентной кооперации позволяет осуществлять международные процедуры подачи заявки, поиска и предварительной экспертизы, но не исключает необходимости получения национальных патентов, которые определяют охрану и защиту прав по национальному праву.

Обращение к наиболее авторитетным международным соглашениям по вопросам интеллектуальной собственности свидетельствует, что универсальное международно-правовое регулирование не затрагивает автономность национального права интеллектуальной собственности различных государств. Благодаря унификационным требованиям международных соглашений, особенно ТРИПС, основные правила национальных законов об интеллектуальной собственности схожи. Вместе с тем различия очень существенны. В США и некоторых других странах системы общего права первоначально авторские права могут возникнуть у юридического лица; в странах континентальной системы права и в России автором может быть только физическое лицо. По-разному решается распределение прав на служебные произведения в странах континентальной системы права и в России, с одной стороны, и в странах системы общего права, с другой стороны. В отличие от большинства стран, включая Россию, некоторые страны (США, Германия) допускают возникновение прав на товарный знак в результате использования обозначения. Специфична патентная система США, исходящая из принципа «первого изобретателя», а не «первого заявителя». Таких примеров можно привести еще очень много. Практически по любому вопросу интеллектуальной собственности возможна коллизия законов.

Размещение произведения на сайте в глобальной информационной сети Интернет, распространение товаров, воплощающих товарные знаки, в международном масштабе и другие варианты трансграничного использования объектов интеллектуальной собственности предполагают наличие иностранного элемента в отношениях. Следовательно, не исключена вероятность применения методов коллизионного регулирования. В международном частном праве особым образом осуществляется соотношение права страны суда как права государства, в котором заявлено требование об охране и защите интеллектуальной собственности, и иностранного права по месту возникновения прав, по национальности правообладателя или по другим локализующим факторам.

В учебной литературе по международному частному праву подчеркивается территориальный характер прав интеллектуальной 
собственности, а коллизионное регулирование в этой области практически не рассматривается ${ }^{4}$. Раз национальные законы об интеллектуальной собственности не имеют силы за границей, то и оснований для коллизионных норм нет. Разделы учебных изданий по международному частному праву преимущественно посвящены описанию международных соглашений в области интеллектуальной собственности и норм национального законодательства по охране интеллектуальных прав иностранцев.

Между тем в современных источниках международного частного права постепенно расширяется коллизионное регулирование в области интеллектуальной собственности. Есть две группы вопросов, которые получают регламентацию: охрана интеллектуальных прав и договоры по вопросам интеллектуальной собственности.

Специальная коллизионная норма об охране интеллектуальных прав была включена в модельный Гражданский кодекс, разработанный Межпарламентской Ассамблеей СНГ, - это ст. $1232^{5}$. Согласно п. 1 данной нормы, к правам на интеллектуальную собственность должно применяться право страны, где испрашивается их защита. Данное правило вошло в ряд законодательных актов государств - участников СНГ по международному частному праву; например, оно закреплено в п. 1 ст. 1132 Гражданского кодекса Республики Беларусь ${ }^{6}$. Это правило разрешения коллизий по вопросам охраны интеллектуальных прав признано в международном частном праве ЕС. Регламент Европейского парламента и Совета ЕС от 11 июля 2008 г. «О праве, применимом к внедоговорным обязательствам» (Regulation of the European Parliament and of the Council № 864/2007 of 11 July 2007 on the law applicable to non-contractual obligations, известен как «Рим 2» или «второй римский регламент») регулирует коллизионные вопросы внедоговорных отношений интеллектуальной собственности. В преамбуле регламента

4 Звеков В. П. Международное частное право. М.: Издательская группа ИНФРА-М, 1999. С. 378; Международное частное право / Л. П. Ануфриева [и др.]. 2-е изд. М. : ТК Велби «Проспект», 2006. С. 298; Федосеева Г. Ю. Международное частное право. 2-е изд. М. : Профобразование, 2000. С. 268.

${ }^{5}$ Модельный Гражданский кодекс для государств - участников СНГ / Модельные законы и кодексы / Межпарламентская Ассамблея CHГ URL: http://www.iacis.ru/html/index. php?id=22\&nid=1\&pag=151\&find=гражданский\%20кодекс. (дата обращении: 20.03 .09 г.) 6 Гражданский кодекс Республики Беларусь: принят Палатой представителей 28 октября 1998 г.: одобрен Советом Республики 19 ноября 1998 г.: текст по состоянию на 8 августа 2008 г. [Электронный ресурс] / СООО «ИПА» Регистр». [Минск, 2008]. Доступ из справ-правовой системы ЮСИАС 6.0. 
сказано, что применительно к нарушениям прав интеллектуальной собственности следует сохранить универсально признанный принцип применения права по месту испрашивания охраны. Соответствующая коллизионная норма содержится в п. 1 ст. 8 второго римского регламента ${ }^{7}$.

Коллизионный принцип для отношений интеллектуальной собственности, «право страны, где испрашивается охрана», или lex loci protectionis, фактически представляет собой «право страны суда», или lex fori. Следовательно, отрицается возможность отсылки к иностранному праву по вопросам охраны интеллектуальных прав. В разделе VI «Международное частное право» третьей части Гражданского кодекса Российской Федерации нет норм, закрепляющих lex loci protectionis применительно к охране интеллектуальной собственности собственности ${ }^{8}$. Толковать эту ситуацию можно двояко:

1) охрана и защита интеллектуальной собственности вообще не входит в предмет коллизионного регулирования, либо

2) жесткая привязка «lex loci protectionis» не является единственным и наиболее эффективным правилом разрешения коллизий и возможно применение открытой коллизионной привязки, содержащейся в п. 2 ст. 1186 Гражданского кодекса Российской Федерации.

Современные явления в развитии российского права интеллектуальной собственности дают основания склоняться в пользу второго варианта. Коллизионные вопросы интеллектуальных прав прямо не обозначены в четвертой части Гражданского кодекса Российской Федерации 9 . Однако в ней содержатся правила, регулирующие отношения с иностранным элементом по вопросам охраны интеллектуальных прав. В частности, ст. 1231, 1256, 1304, 1321, 1328, 1332, 1336, $1341,1346,1359,1382,1434,1438,1457,1495,1517,1522,1531,1536$

${ }^{7}$ Regulation of the European Parliament and of the Council № 864/2007 of 11 July 2007 on the law applicable to non-contractual obligations // Official Journal of the European Community. 2007. L. 199. P. 40-49.

8 Гражданский кодекс Российской Федерации. Часть третья от 26 нояб. 2001 г. № 146Ф3 : принят Гос. Думой Федер. Собр. Рос. Федерации 1 нояб. 2001 г. : одобр. Советом Федерации Федер. Собр. Рос. Фелерации 14 нояб. 2001 г. : ввод. Федер законом Рос. Федерации от 26 нояб. 2001 г. № 147-Ф3 // Собр. законодательства Рос. Федерации. 2001. № 49, ст. 4552.

9 Гражданский кодекс Российской Федерации. Часть четвертая от 18 дек. 2006 г. № 230-Ф3 : принят Гос. Думой Федер. Собр. Рос. Федерации 24 нояб. 2006 г. : одобр. Советом Федерации Федер. Собр. Рос. Федерации 8 дек. 2006 г. : ввод. Федер. законом Рос. Федерации от 18 дек. 2006 г. № 231-Ф3 // Собр. законодательства Рос. Федерации. 2006. № 52, ч. 1, ст. 5496. 
Гражданского кодекса Российской Федерации в основном сформулированы исходя из lex loci protectionis. Наиболее явно к интеллектуальной собственности в целом применение этого принципа следует из формулировки п. 2 ст. 1231 Гражданского кодекса Российской Федерации: «При признании исключительного права на результат интеллектуальной деятельности или на средство индивидуализации в соответствии с международным договором Российской Федерации содержание права, его действие, ограничения, порядок его осуществления и защиты определяются настоящим Кодексом независимо от положений законодательства страны возникновения исключительного права, если таким международным договором или настоящим Кодексом не предусмотрено иное».

Вместе с тем исключения из lex loci protectionis в четвертой части Гражданского кодекса Российской Федерации получили довольно широкое признание. В частности, возможность применения иностранного права по вопросам охраны интеллектуальных прав следует из п. 3 и абз. 2 п. 4 ст. 1256, п. 3 ст. 1304, п. 1. 3) и п. 2 ст. 1341, п. 1) ст. 1359, п. 2 ст. 1517, абз. 3 п. 5 ст. 1522, абз. 2 п. 2 ст. 1531, п. 1. 2) ст. 1536 Гражданского кодекса Российской Федерации.

Например, согласно п. 3 ст. 1256 Гражданского кодекса Российской Федерации право государства, на территории которого имел место юридический факт, послуживший основанием для приобретения авторских прав, определяет автора произведения или иного первоначального правообладателя при предоставлении на территории Российской Федерации охраны произведению в соответствии с ее международными договорами. В данном случае коллизия между российским и иностранным авторским правом решается по привязке lex loci actus.

Применение иностранного права в договорных отношениях интеллектуальной собственности имеет гораздо больше оснований, чем в отношениях, связанных с ее охраной. К договорам с иностранным элементом по вопросам интеллектуальной собственности право определяется по общим коллизионным привязкам:

- «место совершения сделки»;

- «автономия воли»;

- «место учреждения, жительства, деятельности стороны, осуществляющей решающее исполнение»;

- «право страны, с которой договор наиболее тесно связан».

Они применяются в отсутствие специального указания. В частности, на основании правил ст. 1210 Гражданского кодекса Российской 
Федерации стороны договора о распоряжении исключительным правом могут самостоятельно выбрать право, регулирующее их права и обязанности по этому договору.

В российском праве коллизионные вопросы договорных обязательств в области интеллектуальной собственности в общей норме не обозначены. Тогда как согласно п. 2 ст. 1232 Модельного Гражданского кодекса СНГ, договоры, имеющие своим предметом права на интеллектуальную собственность, регулируются правом, определяемым согласно коллизионным нормам о договорных обязательствах. Данное положение не вошло в шестой раздел Гражданского кодекса Российской Федерации, но есть в источниках международного частного права других государств-участников СНГ (ст. 36 Закона Украины «О международном частном праве» ${ }^{10}$, п. 2 ст. 1132 Гражданского Кодекса Республики Беларусь).

Вместе с тем, в п. 3.19) ст. 1211 Гражданского кодекса Российской Федерации выделены лицензионные договоры и для них указана привязка «право лицензиара». В силу того, что эта разновидность договоров по вопросам интеллектуальной собственности получила широкое распространение, в источниках международного частного права, для нее, как правило, всегда содержатся специальные коллизионные правила (п. 1.15) ст. 1225 Модельного Гражданского кодекса СНГ, п. 1.20) ст. 44 Закона Украины «О международном частном праве», п. 1.15) ст. 1125 Гражданского кодекса Республики Беларусь). Отсутствие общей нормы, распространяющей правила раздела VI «Международное частное право» третьей части Гражданского кодекса Российской Федерации на любые договоры по вопросам интеллектуальной собственности не должно служить препятствием для применения к ним ст. 1210, 1211 и других коллизионных норм о договорах. Причем, критерий наиболее тесной связи по правилам ст. 1211 может быть установлен не только по месту нахождения стороны, осуществляющей решающее исполнение, но и по другим признакам, принимая во внимание условия и существо договора или совокупность обстоятельств дела.

В ходе развития коллизионного регулирования появляются новые специальные коллизионные привязки для определения применимого права в договорных отношениях в области интеллектуальной

10 Закон України «Про міжнародне приватне право» від 23 червня 2005 року № 2709IV // Відомості Верховної Ради. 2005. № 32, ст. 422. URL: http://zakon.rada.gov.ua/ cgi-bin/laws/main.cgi?nreg=2709-15 (дата обращения: 12.10.2009). 
собственности. Регламент Европейского парламента и Совета ЕС от 17 июня 2008 г. «О праве, применимом к договорным обязательствам» (Regulation of the European Parliament and of the Council № 593/2008 of 17 June 2008 on the law applicable to contractual obligations, известен как «Рим 1» или «первый римский регламент») не выделяет договоры по вопросам интеллектуальной собственности в отдельную группу. При отсутствии автономии воли к ним применяется право страны, в которой имеет местонахождение сторона, исполняющая основное обязательство (ст. 4 Регламента) ${ }^{11}$. Но в первом римском регламенте сделано исключение для франчайзинговых соглашений. При отсутствии выбора применимого права по соглашению сторон оно определяется по коллизионной привязке «право франчайзи».

Таким образом, нельзя отрицать наличие оснований для постановки коллизионного вопроса применительно к интеллектуальной собственности. Закрепление в третьей части Гражданского кодекса Российской Федерации открытых коллизионных привязок, преимущественное применение критерия наибольшей тесной связи, а также ссылки на иностранное право об интеллектуальной собственности в его четвертой части предоставляют довольно широкий круг оснований для отсылки к иностранному праву.

Безусловно, территориальность интеллектуальной собственности значительным образом ограничивает эту возможность. Правовым обоснованием отказа в применении иностранного права к договору по вопросам интеллектуальной собственности могут служить правила ст. 1192 «Применение императивных норм», ст. 1193 «Оговорка о публичном порядке», ст. 1194 «Реторсии» Гражданского кодекса Российской Федерации.

Применение же иностранного права в соответствии с нормами четвертой части Гражданского кодекса Российской Федерации сводится к тому, что некоторые обстоятельства, обоснованные и являющиеся законными по иностранному праву, являются условием предоставления, ограничения, взаимного признания или прекращения охраны по праву Российской Федерации. Приведем конкретные примеры:

1. Для целей предоставления охраны в Российской Федерации по международным договорам учитывается срок действия

${ }^{11}$ Regulation EC № 593/2008 of the European Parliament and of the Council of 17 June 2008 on the law applicable to contractual obligations // Official Journal of the European Community. 2008. Vol. 51. L. 177. P. 6-16. 
исключительного права на объекты авторского права и смежных прав по иностранному праву - абз. 2 п. 4 ст. 1256, п. 3. 1304 Гражданского кодекса Российской Федерации.

2. На условиях взаимности определяется предоставление охраны исключительного права публикатора (п. 1.3 ст. 1341 Гражданского кодекса Российской Федерации) и свободное использование объектов промышленной собственности в транспортных средствах и космической технике (п. 1 ст. 1359 Гражданского кодекса Российской Федерации). Правила предоставления и ограничения охраны по российскому праву применяются, если законодательство иностранного государства аналогичным образом применяется в отношении граждан Российской Федерации и объектов, зарегистрированных в Российской Федерации.

3. В Российской Федерации может быть предоставлена охрана в качестве наименования места происхождения товара (НМПТ) наименования географического объекта, который находится в иностранном государстве. Гражданский кодекс Российской Федерации предусматривает, что в таком случае иностранное право определяет возможность охраны права использования НМПТ; лицо, которое может являться правообладателем (п. 2 ст. 1517); требования к документу, подтверждающему право на НМПТ в стране происхождения товара (абз. 3 п. 5 ст. 1522, абз. 2 п. 2 ст. 1531). Необходимость исследования и учета норм иностранного права по НМПТ следует из правил п. 1.2) ст. 1536 Гражданского кодекса Российской Федерации, поскольку утрата иностранным правообладателем прав в стране происхождения товара является основанием прекращения охраны в Российской Федерации.

На сегодняшний день можно выявить закономерность постепенного проникновения иностранного права интеллектуальной собственности в рамки отечественной юрисдикции. Интеллектуальная собственность находится в основном в поле частного права. Вполне вероятно, что коллизионная отсылка к иностранному праву (например, по месту возникновения охраны) с течением времени станет восприниматься так же естественно, как в других отношениях с иностранным элементом. Уже в средние века глоссаторы обосновали необходимость применения иностранного права к отношениям с иностранным элементом. Ответы на возможные вопросы о целесообразности этого применительно к интеллектуальной собственности дают реалии современного глобализованного мира. 
В первом десятилетии XXI в. стремительно обостряется проблема несоответствия территориального характера прав интеллектуальной собственности активизации экономического, социального и культурного взаимодействия. Две основные проблемы, которые вышли в настоящее время на передний план - это либерализация международного оборота товаров и услуг, а также развитие трансграничного виртуального пространства. Мировой оборот контрафактных товаров увеличивается с каждым годом. Подделка лекарств и товарных знаков угрожает жизни и здоровью населения. Проблема в том, что перемещение контрафактных товаров зачастую опережает распространение правовой охраны на рынках их сбыта. Дигитализация, т. е. перевод объектов интеллектуальной собственности в цифровую форму, обеспечивает чрезвычайную легкость их размещения и использования в Интернет и других информационных сетях. В первую очередь это относится к объектам авторского права и смежных прав, однако в виртуальном пространстве широко используются и другие объекты интеллектуальной собственности - промышленные образцы, товарные знаки, изобретения и т. д.

Территориальность интеллектуальной собственности в современном мире - проблема очень сложная и противоречивая. Анализ международного и национального права показывает, что территориальный характер прав интеллектуальной собственности не носит абсолютный характер. По мере расширения возможности взаимодействия и взаимопроникновения национально-правовых систем может появиться универсальная охрана интеллектуальных прав. В западной юридической литературе встречаются даже очень смелые предложения о создании действительно в полном смысле слова международной охраны прав интеллектуальной собственности ${ }^{12}$. С ними нельзя согласиться. В частности, автономные национальные системы охраны исчезнут не скоро, а может быть - никогда. Возможность охраны изобретения или товарного знака во всех странах мира на основе патентования или регистрации в одной стране представляется утопией.

Отказ от территориальности интеллектуальной собственности осложнен национальными политическими интересами государств, которые обостряются в условиях протекционистских тенденций, вызванных мировым экономическим кризисом. Поэтому соответствующие

12 Sterling J. A. L. World copyright law: protection of authors works, performances, phonograms, films, video, broadcasts and published editions in national, international and regional law. 2nd edition. London: Thomson Sweet and Maxwell, 2005. P. 926. 
изменения в международное и национальное право вводятся очень осторожно. Как ни странно, заинтересованность в территориальности интеллектуальной собственности можно найти и у правообладателей. Лицензирование для одного или нескольких государств выгоднее, чем для всех сразу.

Тенденция последовательного ограничения территориальности интеллектуальной собственности в развитии международного и национального права сохранится (ВОИС проводит исследования в этой области $\left.{ }^{13}\right)$. Однако в ближайшем будущем маловероятно заключение новых международных соглашений, содержащих нормы, позволяющие снимать территориальный характер прав интеллектуальной собственности.

Наибольшую озабоченность со стороны международного сообщества вызывает проблема контрафакта. Международный оборот товаров, в котором незаконно используются объекты интеллектуальной собственности, достигает гигантских масштабов. По оценкам международных организаций, объем контрафактной продукции для некоторых стран достигает $100 \%{ }^{14}$. Пиратство и контрафакт стали не менее прибыльным бизнесом для трансграничной преступности, чем торговля наркотиками и оружием. С правовой точки зрения благоприятные условия для этой деятельности предоставляет именно территориальность интеллектуальной собственности. Пересечение национальных границ товарами, незаконно воплощающими объекты интеллектуальной собственности, осуществляется гораздо проще и быстрее, чем охрана интеллектуальных прав в иностранном государстве.

Усилиями одного государства контрафакт не может быть поборен. Но даже по этой животрепещущей проблеме пока не удается достичь консенсус и заключить международное соглашение. Всемирный конгресс по борьбе с контрафактом и пиратством (Global Congress on Combating Counterfeiting and Piracy) проводится с 2004 г. по совместной инициативе ВОИС, Интерпола и Всемирной таможенной организации при поддержке ряда неправительственных организаций (Международной ассоциации по товарным знакам, Международной торговой палаты и др.).

13 The Role of Private International Law and Alternative Dispute Resolution [Electronic resource] / World intellectual property organization / Program Activities. URL: http:/www. wipo.int/copyright/en/ecommerce/ip_survey/chap4.html (дата обращения: 15.05.2008). 14 Идрис К. Интеллектуальная собственность - мощный инструмент экономического роста. Женева : ВОИС, 2004. С. 367. 
Правовые механизмы, с помощью которых международное сообщество планирует остановить международные потоки контрафакта, пока не найдены ${ }^{15}$. Вероятно, одной из причин этого является неготовность государств отказаться от основы территориального характера прав интеллектуальной собственности - отсутствия экстерриториальной силы национальных законов об охране и защите прав исключительных прав.

Переосмысление территориальности интеллектуальной собственности на современном этапе будет осуществляться путем развития национального права и правоприменительной практики. Этот процесс затронет в первую очередь развитые страны, экономика которых становится все более ориентированной на интеллектуальные ресурсы. В частности, дискуссию о новых механизмах ограничения территориальности интеллектуальной собственности в рамках ВОИС инициирует ЕС, где римские регламенты уже обозначили необходимость совершенствования коллизионных норм об интеллектуальной собственности ${ }^{16}$.

\section{Библиографический список}

Звеков В. П. Международное частное право. М. : Издательская группа ИНФРА-М, 1999. 686 с.

Идрис К. Интеллектуальная собственность - мощный инструмент экономического роста. Женева: ВОИС, 2004. 450 с.

Международное частное право / Л. П. Ануфриева [и др.]. 2-е изд. М.: ТК Велби «Проспект», 2006. 688 с.

Федосеева Г. Ю. Международное частное право. 2-е изд. М.: Профобразование, 2000. 320 с.

Dinwoodie Graeme B. Trademarks and territory: detaching trademark law from the nation-state // Houston law review. 2004. Vol. 41. № 10-11. P. 887-973.

Ermert M. ACTA: Negotiations advance «Behind the curtain»; many concerns // Intellectual Property Watch. 02.08.2008. URL: http://www.ipwatch.org/weblog/index.php?p=1186 (дата обращения: 15.08.2008).

15 Ermert M. ACTA: Negotiations advance «Behind the curtain»; many concerns // Intellectual Property Watch. 02.08.2008. URL: http://www.ip-watch.org/weblog/index.php?p=1186 (дата обращения: 25.08.2008).

16 Justifications for Topics Proposed as Future Work by the European Community and Its Member States at the SCCR. Doc. SCCR/17/4 of March 10-12, 2008 / World Intellectual Property Organization. URL: http:/www.wipo.int/edocs/mdocs/copyright/en/sccr_17/ sccr_17_4.doc (дата обращения: 27.07.2009). 
Marshall Leaffer A. The Law World of Internet. Trademark Law // Intellectual Property Law Review. 1998. Vol. 1. № 28. P. 28.

Sterling J. A. L. World copyright law: protection of authors works, performances, phonograms, films, video, broadcasts and published editions in national, international and regional law. 2nd edition. London : Thomson Sweet and Maxwell, 2005.

\section{Territoriality of Intellectual Property at the Contemporary Stage (Summary)}

\section{Elena B. Leanovich*}

The article dwells on territorial character of intellectual property rights in the present conditions of globalization. The author shows grounds for applying conflict of law rules to intellectual property. A comparative analysis of Russian legal norms (the third and the fourth parts of the Civil Code of the Russian Federation) and law of other states (Belarus, Ukraine) is given. The possibility and expediency of governing of certain intellectual property questions by international law are proved.

The author shows a trend of gradual restriction of intellectual property territoriality by international legal regulation using as examples the most famous international agreements on intellectual property. It is pointed out that conclusion of a new international agreements restricting territorial character of intellectual property is currently implausible. The author believes that rejection of the principle of the intellectual property territoriality is to proceed within national legal regulation and case law.

Keywords: intellectual property; conflict of law rules regarding intellectual property; international protection of intellectual property; territorial character of intellectual property; globalization.

\footnotetext{
* Elena B. Leanovich - Ph.D. in Law, assistant professor of the Chair of Private International and European law of the Faculty of International Relations, Belarusian State University. leanovich@rambler.ru.
} 